\title{
Effect of modified atmosphere packaging on the growth of spoilage microorganisms and Listeria monocytogenes on fresh cheese
}

\author{
Stephanie R. B. Brown, ${ }^{*}$ Emily C. Forauer, $†$ and Dennis J. D’Amico*1 \\ *Department of Animal Science, and \\ †Department of Pathobiology and Veterinary Science, University of Connecticut, Storrs 06269
}

\begin{abstract}
Queso Fresco has a limited shelf life and has been shown to support the rapid growth of Listeria monocytogenes during refrigerated storage. In addition to improving quality and extending shelf life, modified atmosphere packaging (MAP) has been used to control the growth of pathogenic microorganisms in foods. The objectives of this study were to determine the effects of MAP conditions on the survival and growth of spoilage microorganisms and L. monocytogenes during storage of Queso Fresco manufactured without starter cultures. For L. monocytogenes experiments, cheeses were surface inoculated at $\sim 4 \log _{10} \mathrm{cfu} / \mathrm{g}$ before packaging. Inoculated and uninoculated (shelf life experiments) cheeses were placed in $75-\mu \mathrm{m}$ high-barrier pouches, packaged under 1 of 7 conditions including air, vacuum, or combinations of $\mathrm{N}_{2}$ and $\mathrm{CO}_{2}$ [100\% $\mathrm{N}_{2}$ (MAP1), $30 \%$ $\mathrm{CO}_{2}: 70 \% \mathrm{~N}_{2}$ (MAP2), $50 \% \mathrm{CO}_{2}: 50 \% \mathrm{~N}_{2}$ (MAP3), or $70 \% \quad \mathrm{CO}_{2}: 30 \% \quad \mathrm{~N}_{2}$ (MAP4), $100 \% \mathrm{CO}_{2}$ (MAP5)], and stored at $7^{\circ} \mathrm{C}$. Samples were removed weekly through $35 \mathrm{~d}$ of storage. Listeria monocytogenes counts were determined for inoculated samples. Uninoculated samples were assayed for mesophilic and psychrotolerant counts, lactic acid bacteria, coliforms, and yeast and mold. In general, cheeses packaged under conditions consisting of higher contents of $\mathrm{CO}_{2}$ had lower $\mathrm{pH}$ levels during storage compared with those stored in conditions with lower levels or no $\mathrm{CO}_{2}$ at all. Similarly, the antimicrobial efficacy of MAP in controlling spoilage microorganisms increased with increasing $\mathrm{CO}_{2}$ content, whereas conditions consisting of $100 \% \mathrm{~N}_{2}$, vacuum, or air were less effective. Mean L. monocytogenes counts remained near inoculation levels for all treatments at d 1 but increased $\sim 2 \log _{10} \mathrm{cfu} / \mathrm{g}$ on cheeses packaged in air, vacuum, and $100 \% \mathrm{~N}_{2}$ (MAP1) conditions at d 7 and an additional $\sim 1.5 \log _{10} \mathrm{cfu} / \mathrm{g}$ at d 14 where they remained through $35 \mathrm{~d}$. In contrast, treatments
\end{abstract}

Received November 29, 2017.

Accepted May 11, 2018.

${ }^{1}$ Corresponding author: ddamico@uconn.edu consisting of $70 \% \mathrm{CO}_{2}$ (MAP4) and $100 \% \mathrm{CO}_{2}$ (MAP5) limited increases in mean $L$. monocytogenes counts to $<1 \log _{10} \mathrm{cfu} / \mathrm{g}$ through $14 \mathrm{~d}$ and $\sim 1.5 \log _{10} \mathrm{cfu} / \mathrm{g}$ by d 21. Mean L. monocytogenes counts increased to levels significantly higher than inoculation (d 0) on cheeses stored in MAP2 and MAP3 on d 21, on d 28 for MAP4, and on d 35 for cheeses stored under MAP5 conditions. Overall, significant treatment $\times$ time interactions were observed between air, vacuum, and MAP1 when each was compared with MAP2, MAP3, MAP4, and MAP5. These data demonstrate that packaging fresh cheese under modified atmospheres containing $\mathrm{CO}_{2}$ may be a promising approach to extend shelf life while limiting L. monocytogenes growth during cold storage.

Key words: Listeria monocytogenes, cheese, modified atmosphere packaging, Queso Fresco

\section{INTRODUCTION}

The Hispanic population in the United States increased by $43 \%$ to 50.5 million people between 2000 and 2010, which was 4 times the growth rate of the total US population at 10\% (Ennis et al., 2011). With the growing Hispanic population and the incorporation of Hispanic cuisine into the American diet, per capita consumption of Hispanic-style cheese has more than doubled over the same period reaching $0.70 \mathrm{lb}$. (0.32 $\mathrm{kg}$ ) in 2010 (Gould, 2017b). Similarly, Hispanic-style cheese production in the United States has grown from 96.3 million lb. in 2000 to more than 266 million lb. in 2016 (Gould, 2017a).

Queso Fresco ( QF) is a soft, unripened, Hispanic-style cheese with a mild, slightly salty flavor and crumbly texture that is popular in ethnic markets and is often a staple in Hispanic households. Although a formal definition and federal standard of identity do not exist, QF has been generally characterized as having a high moisture content $(>50 \%)$, low levels of sodium chloride, and low acidity ( $\mathrm{pH}>5.8$; Van Hekken and Farkye, 2003). Such conditions provide a favorable growth environment for contaminants including bacterial pathogens (Genigeorgis et al., 1991a; Kasrazadeh and Genigeorgis 
1994, 1995). Without a national standard, considerable variation in composition exists. Depending on the microbial and physicochemical compositions of the cheese, the shelf life is typically less than 1 mo and can be as short as 7 d (Villar et al., 1999; Renye et al., 2008; Bermúdez-Aguirre and Barbosa-Cánovas, 2010).

Increasing consumer demand for preservative-free, "clean label" foods favors the use of modified atmosphere packaging (MAP) to extend the shelf life of a variety of foods. Modifying the composition of the gases that surround a food product during storage, including $\mathrm{N}_{2}$ and $\mathrm{CO}_{2}$, can reduce physiological changes, oxidation reactions, and microbial growth (Mastromatteo et al., 2014). However, extending the shelf life of refrigerated foods raises concerns about the growth of the foodborne pathogen Listeria monocytogenes, which can reach high levels rapidly in QF when stored at refrigeration temperatures due to the cheese variety's relatively low acidity and high moisture content (Kozak et al., 2018). According to the Centers for Disease Control and Prevention's National Outbreak Reporting System, 11 listeriosis outbreaks between 2009 and 2015 were linked to cheeses knowingly produced from pasteurized milk, 6 of which were associated with the consumption of Mexican- or Hispanic-style soft cheeses including QF (CDC, 2018). Outbreaks linked to cheese produced from pasteurized milk highlight the need for strategies for controlling L. monocytogenes contamination of postlethality exposed ready-to-eat foods.

The potential of MAP to extend the shelf life of different dairy products has been demonstrated (Khoshgozaran et al., 2012). However, MAP is an under investigated approach for extending shelf life and controlling the growth of L. monocytogenes on $\mathrm{QF}$ and similar cheeses. Given the relatively hospitable composition of QF for supporting microbial growth, this cheese also serves as a worst-case scenario model for other cheeses. Therefore, the objectives of this study were to determine the effects of MAP conditions on the survival and growth of (1) spoilage organisms and (2) L. monocytogenes as surface contaminants on QF during refrigerated storage at $7^{\circ} \mathrm{C}$.

\section{MATERIALS AND METHODS}

\section{Bacterial Strains, Growth Conditions, and Inoculum Preparation}

A cocktail of 8 L. monocytogenes strains was prepared as previously described (Kozak et al., 2018) using strains associated with outbreaks linked to soft cheeses or isolated from cheese processing environments, which included F5069/ATCC 51414 (milk-related outbreak),
CWD 675-3 (Hispanic-style cheese-related outbreak), CWD 1567 (Hispanic-style cheese-related outbreak), Scott A (milk-related outbreak), 2012L-5323 (Ricotta salata cheese-related outbreak), 2014L-6025 (Hispanicstyle cheese-related outbreak), DJD 1 (washed-rind cheese-related outbreak), and CWD 193-10 U5-2 (dairy plant food contact surface). The cocktail was serially diluted in Butterfield's phosphate buffer (BPB), pelleted through centrifugation $(30 \mathrm{~min}, 4,000 \times \mathrm{g}$ at $4^{\circ} \mathrm{C}$; Thermo Scientific Sorvall Legend X1R, Thermo Fisher Scientific, Waltham, MA), and resuspended in $\mathrm{BPB}$ to attain $\sim 7 \log _{10} \mathrm{cfu} / \mathrm{mL}$.

\section{Cheese Manufacture and Analysis}

For L. monocytogenes growth experiments, QF was manufactured in the University of Connecticut Creamery according to a standard protocol using 50 gallons $(189.3 \mathrm{~L})$ of cow milk standardized to $3.5 \%$ fat using pasteurized skim milk and cream (Garelick Farms, Franklin, MA) as previously described (Kozak et al., 2018). Briefly, after filling the vat, calcium chloride was added to the milk at a level of $0.02 \%$ (vol/vol) and thoroughly mixed. Milk temperature was raised to $32^{\circ} \mathrm{C}$ and the $\mathrm{pH}$ was adjusted to 6.45 with dilute lactic acid ( $50 \% \mathrm{vol} /$ vol in sterile water, $85 \%$ lactic acid, Sigma-Aldrich, St. Louis, MO). Chymosin (CHY-MAX DCI Star double strength microbial rennet, Dairy Connection, Madison, WI) was added at a rate of $15.83 \mathrm{~mL} / 100 \mathrm{~L}$, and milk was stirred for approximately $45 \mathrm{~s}$ to mix. Once desired firmness was reached, the coagulum was cut into $1 \times$ $1 \mathrm{~cm}$ curds using sanitized stainless-steel curd knives. Curds were allowed to rest for $5 \mathrm{~min}$ and then stirred for $5 \mathrm{~min}$, which was repeated for 3 cycles for a total of $30 \mathrm{~min}$. After an additional 5 min rest, the majority of the whey was removed by draining. Curds were then transferred to standard 20\# Wilson hoops lined with disposable cheese cloth and pressed at $68.95 \mathrm{kPa}$ for 20 min. Pressed curds were then removed from the hoops, broken into individual curds, and kosher salt (Diamond Crystal, Cargill, Wayzata, MN) was added to obtain a target salt (as sodium chloride) concentration of $\sim 2 \%$ in the final cheese. Salted curds were returned to the hoops and pressed at $68.95 \mathrm{kPa}$ for an additional 75 min. For shelf life experiments, QF was manufactured in the laboratory using a laboratory-scale cheese vat (Labtronix Inc., Philomath, OR) according to the same standard protocol using 6 gallons $(22.7 \mathrm{~L})$ of cow milk standardized to $3.5 \%$ fat using pasteurized skim milk and cream (Price Chopper, Schenectady, NY). The only other change was that curds from laboratory-scale production were transferred to plastic hoops $(15 \times$ 10.5 cm; M605MTF066, Fromagex, Rimouski, Quebec, 
Canada) and pressed at a reading of $60 \mathrm{lb}$. for both pressings. Cheese blocks from both scales of production were vacuum sealed (Ultravac 250, UltraSource LLC, Kansas City, MO) in pouches (3 mil, oxygen transmission rate: $50-70 \mathrm{~mL} / \mathrm{m}^{2} \cdot 24 \mathrm{~h}$; UltraSource LLC) and stored at $4^{\circ} \mathrm{C}$ before cutting into experimental units.

Physiochemical analysis was conducted on representative samples from each independent batch of cheese, in duplicate, at the time of cutting, including pH (potentiometric method; Hooi et al., 2004; Accumet AB150 with microtip electrode, Fisher Scientific International Inc., Hampton, NH), DM (forced draft oven method; Hooi et al., 2004), fat (Babcock method; Hooi et al., 2004), and salt (Quanttab Chloride, Hach, Loveland, CO). The $\mathrm{pH}$ of homogenized samples was also measured in duplicate for each technical replicate at each microbiological sampling point in the shelf life experiments before buffer addition using a sanitized electrode. Salt in moisture (SM), moisture in the nonfat substance (MNFS), and fat in dry matter (FDM) were determined using the following formulae: $\% \mathrm{SM}=$ $[\%$ salt $/(100-\% \mathrm{DM})] \times 100 ; \% \mathrm{MNFS}=[100-\%$ $\mathrm{DM} /(100-\%$ fat $)] \times 100 ;$ and $\% \mathrm{FDM}=(\%$ fat $/ \%$ $\mathrm{DM}) \times 100$. Compositional targets based on previous work included $\sim 52 \%$ moisture, $\sim 22 \%$ fat, $\sim 2.0 \%$ salt, $\mathrm{SM} \sim 4 \%$, MNFS $\sim 45 \%$, and $\mathrm{pH}$ of $\sim 6.4$ (Genigeorgis et al., 1991b; Clark et al., 2001; Kozak et al., 2018).

\section{Cheese Sample Preparation, Inoculation, and Packaging}

Cheeses were cut into $25 \pm 2$ g samples using sterile knives for use in their respective experiments (L. monocytogenes vs. shelf life) within $48 \mathrm{~h}$ of manufacture. For L. monocytogenes growth experiments, cheeses were inoculated with $100 \mu \mathrm{L}$ of the L. monocytogenes suspension in $\mathrm{BPB}$, which was spread over a single surface of the cheese sample with a sterile spreader to attain a target contamination level of $\sim 4 \log _{10} \mathrm{cfu} / \mathrm{g}$ of cheese. Inoculated cheese samples were allowed a 30-min drying period to enable bacterial attachment before packaging.

Inoculated (for L. monocytogenes experiments) and uninoculated (for shelf life experiments) cheese samples were packaged under 1 of 7 different conditions in high-barrier pouches (nylon/ethylene-vinyl alcohol/ polyethylene; $75 \mu \mathrm{m}$; oxygen transmission rate $1.2 \mathrm{~mL} /$ $\mathrm{m}^{2} \cdot 24 \mathrm{~h}$; moisture vapor transmission $4 \mathrm{~g} / \mathrm{m}^{2} \cdot 24 \mathrm{~h}$; DELI*1, Winpak, Winnipeg, Manitoba, Canada) based on previous studies in the literature and industry recommendations (Dansensor, 2017). Conditions included $\begin{array}{lllll}\text { air, vacuum, } 100 \% & \mathrm{~N}_{2} & \text { (MAP1), } 30 \% & \mathrm{CO}_{2}: 70 \% & \mathrm{~N}_{2}\end{array}$ (MAP2), $50 \% \quad \mathrm{CO}_{2}: 50 \% \mathrm{~N}_{2}$ (MAP3), $70 \% \quad \mathrm{CO}_{2}: 30 \%$ $\mathrm{N}_{2}$ (MAP4), and $100 \% \mathrm{CO}_{2}$ (MAP5). Pouches were evacuated, flushed, and sealed in a vacuum packager (Ultravac 250, UltraSource LLC) with gas injection. Gases (Airgas, North Franklin, CT) were mixed using a WITT gas mixer (KM 100-3, WITT Gas Controls LP, Alpharetta, GA). Packager program settings included $99 \%$ vacuum for vacuum and MAP treatments and $10 \%$ vacuum for air conditions. Packaging under MAP conditions (MAP1-5) required the addition of non-ambient gas with the gas setting of the packaging program set to $5 \%$. Dry anaerobic indicator strips (BD BBL, Becton, Dickinson and Company, Sparks, MD) were included with each sample in each package to monitor the presence/absence of $\mathrm{O}_{2}$ over time. Any blue coloration, regardless of strength, was considered positive. All samples were randomly assigned a sampling date (e.g., d 7) and stored at $7^{\circ} \mathrm{C}$ to mimic retail storage and mild temperature abuse along the food supply chain (Kennedy et al., 2005).

\section{Sampling and Enumeration}

In addition to initial counts on d 0 , duplicate samples from each condition were removed from storage on $\mathrm{d} 1$ (for L. monocytogenes only), 7, 14, 21, 28, and 35 postpackaging. The $\mathrm{BPB}$ was added to samples at a sample to medium ratio of 1:4 ( 100 mL of BPB) and homogenized in a Smasher stomacher (Biomerieux, Marcyl'Étoile, France) for $1 \mathrm{~min}$ at 560 strokes/min. Following serial dilutions in $\mathrm{BPB}$, homogenates were plated onto media specific for each target microorganism or groups of microorganisms based on standard methods (Frank and Yousef, 2004; Laird et al., 2004). When applicable, $1 \mathrm{~mL}$ of the homogenate was plated over 4 agar plates (250 $\mu \mathrm{L}$ per plate) to achieve a limit of detection of $\geq 5$ $\mathrm{cfu} / \mathrm{g}$. Briefly, mesophilic microorganisms were enumerated on trypticase soy agar with yeast extract (Difco, Detroit, MI) and incubated at $32^{\circ} \mathrm{C} \pm 1^{\circ} \mathrm{C}$ for $48 \mathrm{~h}$. Psychrotolerant microorganisms were enumerated on trypticase soy agar with yeast extract incubated at $7^{\circ} \mathrm{C}$ $\pm 1^{\circ} \mathrm{C}$ for $10 \mathrm{~d}$. Total lactic acid bacteria (LAB) were enumerated on de Man, Rogosa, and Sharpe (Difco) agar incubated anaerobically at $32^{\circ} \mathrm{C} \pm 1^{\circ} \mathrm{C}$ for 48 h. Samples for yeasts and mold were inoculated onto dichloran rose bengal chloramphenicol agar (DRBC; Difco), incubated at $25^{\circ} \mathrm{C} \pm 1^{\circ} \mathrm{C}$, and examined after 3 , 4 , and $5 \mathrm{~d}$. Reported counts are those enumerated on d 5. Homogenates for coliforms were plated onto Petrifilm Coliform Count plates (3M Microbiology, St. Paul, $\mathrm{MN}$ ) and incubated at $32^{\circ} \mathrm{C} \pm 1^{\circ} \mathrm{C}$ for $24 \mathrm{~h}$. None of the colonies recovered were confirmed by catalase reaction or Gram stain. Listeria monocytogenes counts were enumerated on modified Oxford agar (Difco) following incubation at $37^{\circ} \mathrm{C} \pm 1^{\circ} \mathrm{C}$ for $48 \mathrm{~h}$. Two inoculated 
samples were processed after the bacterial attachment period to verify initial $L$. monocytogenes inoculation levels. Two uninoculated negative controls were also included to verify the absence of $L$. monocytogenes in uninoculated QF based on this enumeration procedure.

\section{Statistical Analysis}

Completely randomized designs with $7 \times 6$ (7 conditions at 6 time points) and $7 \times 7$ ( 7 conditions at 7 time points) factorial treatment structures were followed for shelf life and L. monocytogenes studies, respectively. Two cheese samples were included for each microbiological target/condition/time point/ trial. Listeria monocytogenes growth experiments and shelf life experiments were repeated 4 and 3 times, respectively, using independently produced batches of cheese. Counts from technical replicates for each of the biological replicates were averaged, and data are presented as means \pm standard deviation of the biological replicates. Data from only 2 replicate batches of cheese were included in the analysis of yeast and mold counts due to the presence of rapidly growing mold colonies on DRBC plates in a single replicate that impeded the growth and enumeration of other colonies. Pooled data were analyzed using the PROC GLM procedure of SAS (ver. 9.4, SAS Institute, Cary, NC). To compare changes in $\mathrm{pH}$ or microbial counts between treatments over time, the model included treatment and time as main effects and the interaction of treatment $\times$ time. $\mathrm{pH}$ values and $L$. monocytogenes counts between treatments at individual time points and L. monocytogenes counts between time points within a treatment were also compared using one-way ANOVA. All pairwise comparisons were performed using LSMEANS with the Tukey or Tukey-Kramer method. Significance was defined as $P<0.05$. Inhibition was defined as $<1 \log _{10}$ $\mathrm{cfu} / \mathrm{g}$ increase in mean $L$. monocytogenes counts at a given time point compared with the initial inoculum level (NACMCF, 2010).

\section{RESULTS AND DISCUSSION}

\section{Physicochemical Parameters}

The composition of cheese produced for each of the 2 experiments was similar with the exception of the lower salt content achieved in laboratory-scale cheeses manufactured for shelf-life studies (Table 1). This could be attributed to the differences in production equipment and volume, to differences in personnel making the cheeses in separate locations, or to both. Regardless, the physicochemical properties of experimental QF batches were within target ranges determined to be acceptable to both traditional and nontraditional consumers while also considering the composition of cheeses associated with the presence of Listeria (Genigeorgis et al., 1991b; Clark et al., 2001). As shown in Table 2, the pH of uninoculated cheeses decreased after $7 \mathrm{~d}$ in MAP conditions containing $\mathrm{CO}_{2}$ (MAP2-MAP5). The observed increase in acidity was most likely due to carbonic acid formation, as observed in previous studies (Farber, 1991; Gonzalez-Fandos et al., 2000; Olarte et al., 2002). Carbon dioxide is highly soluble in fat and water and forms carbonic acid, which, in its undissociated form, has antimicrobial activity attributed to alterations in intracellular $\mathrm{pH}$. Treatment and time effects were observed for $\mathrm{pH}$ over $35 \mathrm{~d}$ of storage $(P<0.001)$. The $\mathrm{pH}$ levels of cheeses stored under air, vacuum, MAP1, MAP2, and MAP3 were similar throughout the study, whereas the $\mathrm{pH}$ levels of cheeses stored under MAP4 and MAP5 conditions were only different than air $(P$ $=0.016$ and $P<0.001$, respectively). We also observed differences in $\mathrm{pH}$ through the duration of the study between cheeses stored under MAP5 conditions when compared with vacuum $(P=0.012)$, MAP1 $(P=0.007)$, and MAP2 $(P=0.022)$. When comparing $\mathrm{pH}$ values between treatments at individual time points, we only observed differences in mean $\mathrm{pH}$ between conditions at d 7 and 14 (Table 2). Overall, the changes in $\mathrm{pH}$ are similar to those reported for fresh goat cheese produced without starter culture and stored under varying MAP conditions (Olarte et al., 2002).

Monitoring additional changes in physicochemical parameters was outside the scope of the present study, but we noted that cheese packaged under air showed signs of moisture loss (whey off) by d 7 compared with by d 14 for all other treatments in both experiments (data not shown), but this was not quantified. Gonzalez-Fandos et al. (2000) found that measured moisture loss was similar between fresh cheese packaged under vacuum and air, which differed significantly from cheeses packaged under different atmospheres containing $\mathrm{CO}_{2}$.

Table 1. Composition (mean \pm SD) of Queso Fresco for experiments 1 (shelf life, $\mathrm{n}=3$ ) and 2 (growth of Listeria monocytogenes, $\mathrm{n}=4$ )

\begin{tabular}{lcc}
\hline Item $^{1}$ & Experiment 1 & Experiment 2 \\
\hline DM (\%) & $46.7 \pm 0.7$ & $46.7 \pm 0.8$ \\
Moisture (\%) & $53.3 \pm 0.7$ & $53.3 \pm 0.8$ \\
Fat (\%) & $21.3 \pm 1.0$ & $20.7 \pm 1.2$ \\
Salt (\%) & $1.6 \pm 0.2$ & $2.1 \pm 0.1$ \\
MNFS (\%) & $67.0 \pm 0.5$ & $67.2 \pm 1.6$ \\
SM (\%) & $3.3 \pm 0.3$ & $3.9 \pm 0.2$ \\
FDM (\%) & $43.8 \pm 2.3$ & $44.2 \pm 2.7$ \\
pH & $6.49 \pm 0.07$ & $6.45 \pm 0.02$ \\
\hline
\end{tabular}

${ }^{1} \mathrm{MNFS}=$ moisture in the nonfat substance; $\mathrm{SM}=$ salt in moisture; $\mathrm{FDM}=$ fat in DM. 
Table 2. $\mathrm{pH}$ of uninoculated Queso Fresco during storage at $7^{\circ} \mathrm{C}$ for $35 \mathrm{~d}$

\begin{tabular}{|c|c|c|c|c|c|c|}
\hline Treatment $^{1}$ & \multicolumn{6}{|c|}{$\mathrm{pH}($ mean $\pm \mathrm{SD})$} \\
\hline Air & $6.49 \pm 0.07$ & $6.49 \pm 0.02^{\mathrm{AB}}$ & $6.36 \pm 0.07^{\mathrm{A}}$ & $6.37 \pm 0.12$ & $6.35 \pm 0.07$ & $6.41 \pm 0.07$ \\
\hline MAP1 & $6.49 \pm 0.07$ & $6.55 \pm 0.15^{\mathrm{A}}$ & $6.40 \pm 0.05^{\mathrm{A}}$ & $6.23 \pm 0.33$ & $6.24 \pm 0.23$ & $6.30 \pm 0.37$ \\
\hline MAP2 & $6.49 \pm 0.07$ & $6.33 \pm 0.10^{\mathrm{ABC}}$ & $6.31 \pm 0.02^{\mathrm{AB}}$ & $6.26 \pm 0.12$ & $6.34 \pm 0.08$ & $6.38 \pm 0.07$ \\
\hline MAP3 & $6.49 \pm 0.07$ & $6.28 \pm 0.04^{\mathrm{BC}}$ & $6.32 \pm 0.10^{\mathrm{AB}}$ & $6.23 \pm 0.10$ & $6.29 \pm 0.05$ & $6.34 \pm 0.08$ \\
\hline
\end{tabular}

${ }^{\mathrm{A}-\mathrm{C}}$ Values within a column with different superscripts differ $(P<0.05)$.

${ }^{1} \mathrm{MAP} 1=100 \% \mathrm{~N}_{2} ; \mathrm{MAP} 2=30 \% \mathrm{CO}_{2}: 70 \% \mathrm{~N}_{2} ; \mathrm{MAP} 3=50 \% \mathrm{CO}_{2}: 50 \% \mathrm{~N}_{2} ; \mathrm{MAP} 4=70 \% \mathrm{CO}_{2}: 30 \% \mathrm{~N}_{2} ; \mathrm{MAP}^{2}=100 \% \mathrm{CO}_{2}$.

Table 3 shows the detection of oxygen in packages for the shelf life experiments based on anaerobic indicator test strips. Similar trends were observed in the L. monocytogenes experiments (data not shown). The number of positive strips in packages decreased during storage for air conditions. This is most likely the result of the consumption of $\mathrm{O}_{2}$ and production of $\mathrm{CO}_{2}$ by microbial activity and cheese respiration (Olarte et al., 2002; Khoshgozaran et al., 2012). Observed increases in the presence of $\mathrm{O}_{2}$ in samples during storage under vacuum may be the result of residual oxygen, packaging permeability, or incomplete seals. Positive indicators were typically not detected in MAP conditions with the exception of slight color changes (light blue indicators) recorded for single technical replicates of MAP1, MAP5, and MAP4 at d 14, 28, and 35, respectively, as well as 2 samples of MAP 5 at $d 21$. This could have resulted from test strip failures, packaging permeability, or the presence of small amounts of $\mathrm{O}_{2}$ from incomplete seals. Regardless, the presence of positive test strips in MAP samples does not appear to have affected mean microbial counts as described below. According to a review by Khoshgozaran et al. (2012), $\mathrm{CO}_{2}$ levels may decrease as $\mathrm{CO}_{2}$ dissolves into the cheese matrix, is consumed by anaerobic microorganisms, or permeates out of the package. Losses of 2 to $5 \% \mathrm{CO}_{2}$ have been reported for MAP packaged cheese $\left(\mathrm{CO}_{2}\right.$ permeability of less than $13 \mathrm{~mL} / \mathrm{m}^{2} \cdot 24 \mathrm{~h}$ and $\mathrm{O}_{2}$ permeability of 5 $\mathrm{mL} / \mathrm{m}^{2} \cdot 24 \mathrm{~h}$ ) over its shelf life (Olarte et al., 2002).

\section{Effect of MAP on Mesophile Counts}

Overall, we observed treatment and time effects $(P<$ 0.001) on mesophile counts (Figure 1). Counts over the duration of the study for cheeses packaged under air differed from MAP3 $(P=0.047)$, MAP4 $(P=0.017)$, and MAP5 $(P<0.001)$ conditions. Counts for cheeses packaged under vacuum or $100 \% \mathrm{~N}_{2}$ (MAP1) also differed from MAP3 $(P=0.022$ and 0.023 , respectively), MAP4 $(P=0.007$ and $P=0.007$, respectively), and MAP5 $(P<0.001$ and $P<0.001$, respectively) over the duration of the study. No differences in mean counts were detected between treatments based on pairwise comparisons at individual time points (Figure 1). As shown in Figure 1, mean counts increased $\sim 2 \log _{10} \mathrm{cfu} / \mathrm{g}$ at $\mathrm{d} 7$ in cheeses stored under air $(4.47$ $\left.\log _{10} \mathrm{cfu} / \mathrm{g}\right)$, vacuum $\left(4.27 \log _{10} \mathrm{cfu} / \mathrm{g}\right.$ ), and $100 \% \mathrm{~N}_{2}$ (MAP1; $\left.4.22 \log _{10} \mathrm{cfu} / \mathrm{g}\right)$ conditions. Mean mesophile

Table 3. Results of anaerobic test strips in uninoculated Queso Fresco sample packages (including technical replicates) under modified atmospheres during storage at $7^{\circ} \mathrm{C}$ for $35 \mathrm{~d}$

\begin{tabular}{|c|c|c|c|c|c|}
\hline \multirow[b]{2}{*}{ Condition $^{1}$} & \multicolumn{5}{|c|}{ No. of positive samples/total no. of samples ${ }^{2}$} \\
\hline & $7 \mathrm{~d}$ & $14 \mathrm{~d}$ & $21 \mathrm{~d}$ & $28 \mathrm{~d}$ & $35 \mathrm{~d}$ \\
\hline$\overline{\text { Air }}$ & $6 / 6$ & $3 / 4^{3}$ & $3 / 6$ & $3 / 6$ & $2 / 6$ \\
\hline Vacuum & $4 / 6$ & $3 / 4$ & $6 / 6$ & $6 / 6$ & $6 / 6$ \\
\hline MAP1 & $0 / 6$ & $1 / 4$ & $0 / 6$ & $0 / 6$ & $0 / 6$ \\
\hline MAP2 & $0 / 6$ & $0 / 4$ & $0 / 6$ & $0 / 6$ & $0 / 6$ \\
\hline MAP3 & $0 / 6$ & $0 / 4$ & $0 / 6$ & $0 / 6$ & $0 / 6$ \\
\hline MAP4 & $0 / 6$ & $0 / 4$ & $0 / 6$ & $0 / 6$ & $1 / 6$ \\
\hline MAP5 & $0 / 6$ & $0 / 4$ & $2 / 6$ & $1 / 6$ & $0 / 6$ \\
\hline
\end{tabular}

${ }^{1} \mathrm{MAP} 1=100 \% \mathrm{~N}_{2} ; \mathrm{MAP} 2=30 \% \mathrm{CO}_{2}: 70 \% \mathrm{~N}_{2} ; \mathrm{MAP} 3=50 \% \mathrm{CO}_{2}: 50 \% \mathrm{~N}_{2} ; \mathrm{MAP} 4=70 \% \mathrm{CO}_{2}: 30 \% \mathrm{~N}_{2} ; \mathrm{MAP} 5$ $=100 \% \mathrm{CO}_{2}$.

${ }^{2}$ Indicator strip results not recorded after packaging on d 0 .

${ }^{3}$ Results not recorded for 1 biological replicate of each condition at 14-d time point. 


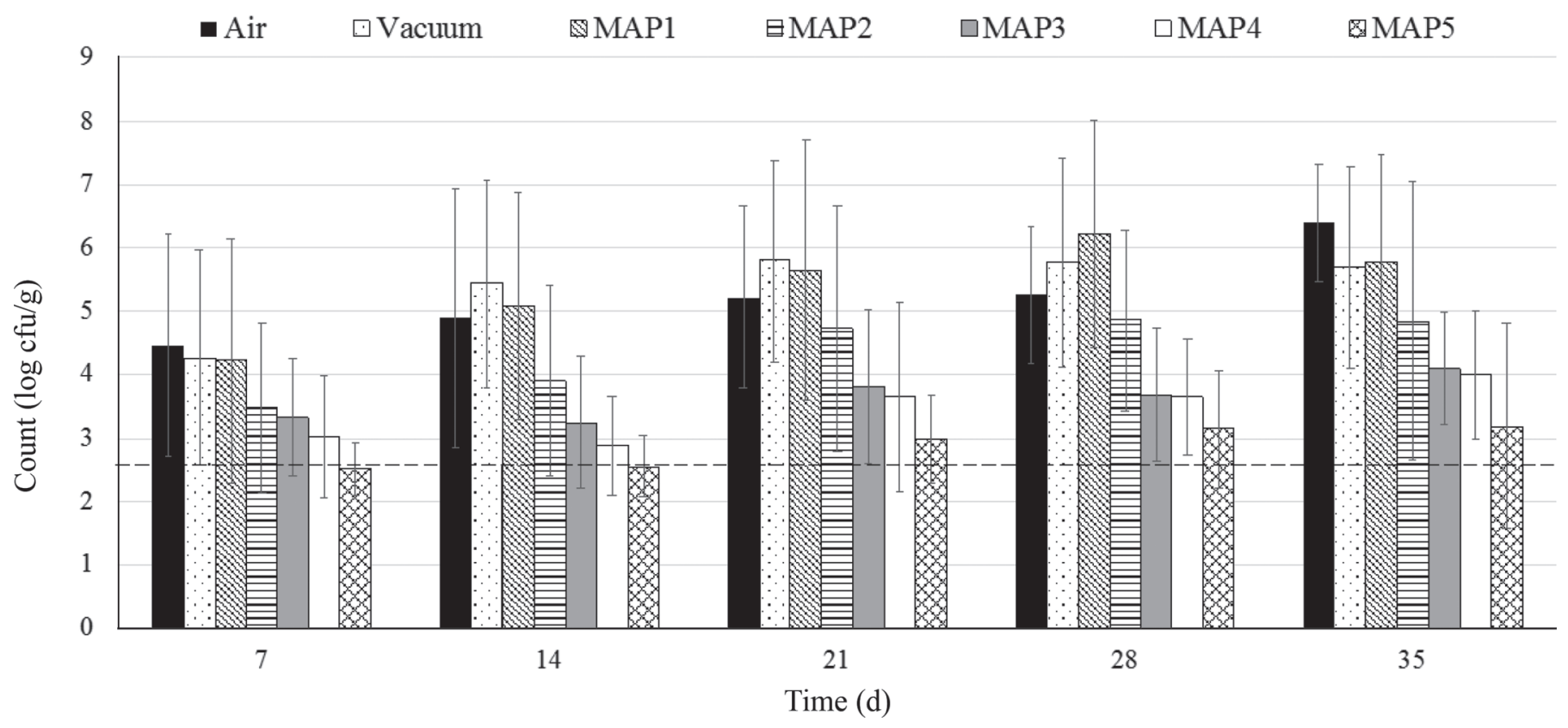

Figure 1. Mean mesophilic count $( \pm \mathrm{SD})$ in Queso Fresco packaged under modified atmospheres during storage at $7^{\circ} \mathrm{C}$ for 35 d. $\mathrm{MAP} 1=$ $100 \% \mathrm{~N}_{2} ; \mathrm{MAP} 2=30 \% \mathrm{CO}_{2}: 70 \% \mathrm{~N}_{2} ;$ MAP3 $=50 \% \mathrm{CO}_{2}: 50 \% \mathrm{~N}_{2} ; \mathrm{MAP} 4=70 \% \mathrm{CO}_{2}: 30 \% \mathrm{~N}_{2} ;$ MAP5 $=100 \% \mathrm{CO}_{2}$. The dashed line indicates initial contamination level at d $0\left(2.68 \pm 0.54 \log _{10} \mathrm{cfu} / \mathrm{g}\right)$.

counts exceeded $6 \log _{10} \mathrm{cfu} / \mathrm{g}$ in the MAP1 treatment $\left(100 \% \mathrm{~N}_{2}\right)$ on $\mathrm{d} 28$ and the air treatment on $\mathrm{d} 35$. In contrast, mean counts remained $<4 \log _{10} \mathrm{cfu} / \mathrm{g}$ through $28 \mathrm{~d}$ under the MAP3 conditions $\left(3.68 \log _{10} \mathrm{cfu} / \mathrm{g}\right)$ and $35 \mathrm{~d}$ for both the MAP4 and MAP5 conditions, with growth inhibited to $<1 \log _{10} \mathrm{cfu} / \mathrm{g}$ through $35 \mathrm{~d}$ (3.19 $\left.\log _{10} \mathrm{cfu} / \mathrm{g}\right)$ in cheeses held under MAP5 $\left(100 \% \mathrm{CO}_{2}\right)$ conditions. A similar trend was observed in mesophilic counts in fresh goat cheese packaged under similar conditions (Gonzalez-Fandos et al., 2000; Olarte et al., 2002). Similarly, total viable counts in low-moisture Mozzarella cheese samples packaged in atmospheres having high $\mathrm{CO}_{2}$ concentrations $\left(50 \% \mathrm{CO}_{2}: 50 \% \mathrm{~N}_{2}\right.$ and $75 \% \mathrm{CO}_{2}: 25 \% \mathrm{~N}_{2}$ :) were less than those packaged in air or with low $\mathrm{CO}_{2}$ levels and high $\mathrm{N}_{2}$ levels $\left(25 \% \mathrm{CO}_{2}\right.$ : $75 \% \mathrm{~N}_{2}$ ) through $28 \mathrm{~d}$ of storage (Mastromatteo et al., 2014). Alam and Goyal (2011) also reported that the plate counts in Mozzarella cheese stored for $12 \mathrm{wk}$ were lowest in samples packed under $100 \% \mathrm{CO}_{2}$ and highest in vacuum-packaged samples.

\section{Coliform Counts}

No coliforms were detected in any batch of cheese produced for the shelf life experiments. However, previous research suggests that the growth of coliforms would be suppressed when exposed to higher concentrations of $\mathrm{CO}_{2}$ (Rosenthal et al., 1991; Gonzalez-Fandos et al., 2000).

\section{Effect of MAP on Psychrotolerant Counts}

Initial mean psychrotolerant counts in QF $\left(5.40 \log _{10}\right.$ $\mathrm{cfu} / \mathrm{g})$ were just below the threshold of $6 \log _{10} \mathrm{cfu} / \mathrm{g}$ used in previous studies based on detectable organoleptic changes in milk (Figure 2; Bishop and White, 1986). Mean counts reached or exceeded this threshold in the air $\left(7.53 \log _{10} \mathrm{cfu} / \mathrm{g}\right)$, vacuum $\left(6.17 \log _{10}\right.$ $\mathrm{cfu} / \mathrm{g}$ ), and MAP1 (6.03 $\log _{10} \mathrm{cfu} / \mathrm{g}$ ) conditions at $\mathrm{d}$ 7. Mean counts remained below this threshold for 28 d under MAP3 conditions (5.42 $\log _{10} \mathrm{cfu} / \mathrm{g}$ ) and $35 \mathrm{~d}$ for both MAP4 $\left(5.22 \log _{10} \mathrm{cfu} / \mathrm{g}\right)$ and MAP5 conditions $\left(4.98 \log _{10} \mathrm{cfu} / \mathrm{g}\right)$. Mean counts in the latter 2 conditions at $35 \mathrm{~d}$ did not exceed initial counts at $\mathrm{d}$ 0 . In contrast, mean counts exceeded $8 \log _{10} \mathrm{cfu} / \mathrm{g}$ in the air treatment at d 14 and remained at this level through 35 d. Overall, we observed a treatment effect on psychrotolerant counts $(P<0.001)$. Psychrotolerant counts through the duration of the study differed between air and MAP2-5 treatments $(P<0.001)$ and counts in cheeses under MAP1 conditions were higher than QF samples under MAP3 $(P=0.032)$, MAP4 $(P$ $<0.001)$, and MAP5 $(P<0.001)$ conditions. Counts in $\mathrm{QF}$ stored under vacuum also differed from both MAP4 and MAP5 $(P=0.004$ and $<0.001$, respectively $)$ through the duration of the study. Differences in counts between treatments at specific time points were only observed on d 14 (air vs. MAP5) as shown in Figure 2. These results are in agreement with those previously 


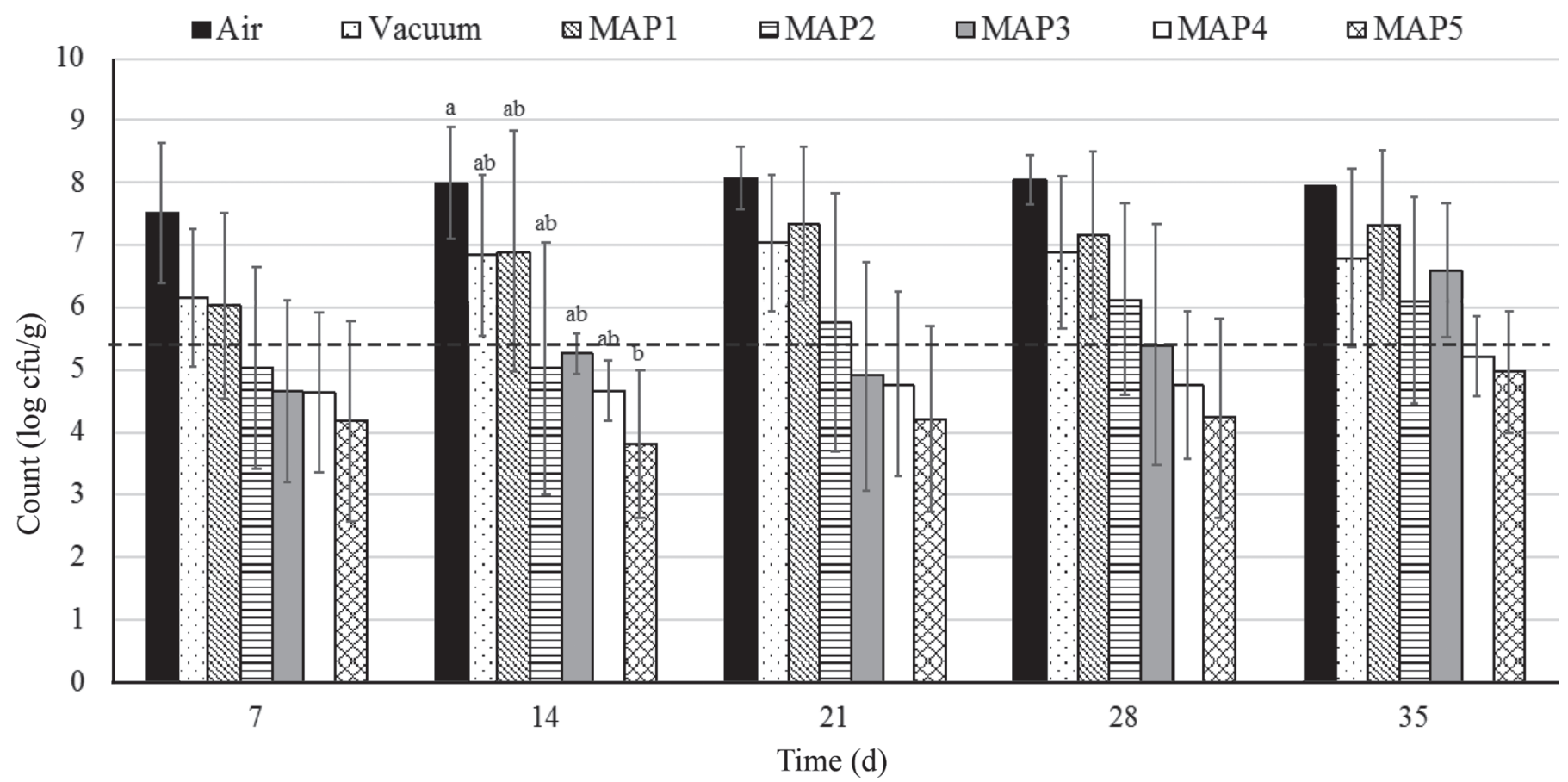

Figure 2. Mean psychrotolerant count $( \pm \mathrm{SD})$ in Queso Fresco samples packaged under modified atmospheres during storage at $7^{\circ} \mathrm{C}$ for 35 d. $\mathrm{MAP} 1=100 \% \mathrm{~N}_{2} ; \mathrm{MAP} 2=30 \% \mathrm{CO}_{2}: 70 \% \mathrm{~N}_{2} ; \mathrm{MAP} 3=50 \% \mathrm{CO}_{2}: 50 \% \mathrm{~N}_{2} ; \mathrm{MAP} 4=70 \% \mathrm{CO}_{2}: 30 \% \mathrm{~N}_{2} ; \mathrm{MAP}^{2}=100 \% \mathrm{CO}_{2}$. The dashed line indicates initial contamination level at d $0\left(5.40 \pm 0.51 \log _{10} \mathrm{cfu} / \mathrm{g}\right)$. ${ }^{\mathrm{a}, \mathrm{b}}$ Values within a time point with different letters differ $(P<0.05)$.

reported for whey cheese (Dermiki et al., 2008), fresh goat cheese (Gonzalez-Fandos et al., 2000; Olarte et al., 2002), and Mozzarella (Alam and Goyal, 2011) cheese, where psychrotolerant growth was lower when the $\mathrm{CO}_{2}$ concentration increased, with $100 \% \mathrm{CO}_{2}$ conditions being the most effective for inhibiting growth. These observations are consistent with the suggestion that most psychrotolerant bacteria in dairy products are aerobic, gram-negative bacteria, which are generally more sensitive to $\mathrm{CO}_{2}$ than gram-positive bacteria (Rosenthal et al., 1991). It is important to note that not all colonies enumerated for psychrotolerant counts in the present study were verified as bacteria nor were their Gram reactions determined. High psychrotolerant counts could be explained by the use of pasteurized milk purchased at retail, but data are not available to support this suggestion.

\section{Effect of MAP on Lactic Acid Bacteria Counts}

Because no starter culture was used in the manufacture of QF in the present study, initial LAB counts were relatively low $\left(1.59 \log _{10} \mathrm{cfu} / \mathrm{g}\right)$. However, populations increased by $>4 \log _{10} \mathrm{cfu} / \mathrm{g}$ at $35 \mathrm{~d}$ for cheeses packaged with air. Counts also increased under all MAP conditions (Figure 3), which is in agreement with the literature as LAB are typically facultative anaerobes (Khoshgozaran et al., 2012). No differences in mean counts were detected between treatments based on pairwise comparisons at individual time points (Figure $3)$. We observed overall treatment and time effects $(P$ $<0.001$ ) on counts; however, no significant interaction between terms was observed. The LAB counts in QF stored in air differed from MAP5 $\left(100 \% \mathrm{CO}_{2} ; P=\right.$ 0.001) through the duration of the study. Mean LAB counts in cheese under MAP5 conditions reached 2.70 $\log _{10} \mathrm{cfu} / \mathrm{g}$ after $35 \mathrm{~d}$. The LAB counts in cheeses under MAP3, MAP4, and MAP5 differed from vacuum $(P$ $=0.043, P=0.067$, and $P<0.001$, respectively) and MAP1 $(P=0.040, P=0.063$, and $P<0.001$, respectively) through the duration of the study. Despite the increase in counts, corresponding reductions in $\mathrm{pH}$ were not observed. Because we did not conduct additional tests to confirm if isolates produced acid, it is possible that they were not significant acid producers in QF. It is also possible that the yeast growth resulted in metabolism of lactic acid, which is supported by the lower $\mathrm{pH}$ of vacuum-packaged samples that inhibited yeast growth compared with those packaged under air, whose $\mathrm{pH}$ remained relatively stable.

\section{Effect of MAP on Yeast and Mold Counts}

Colonies enumerated on DRBC were consistently identified as yeast but are reported as yeast and mold for comparison with previous studies. Similar to psy- 


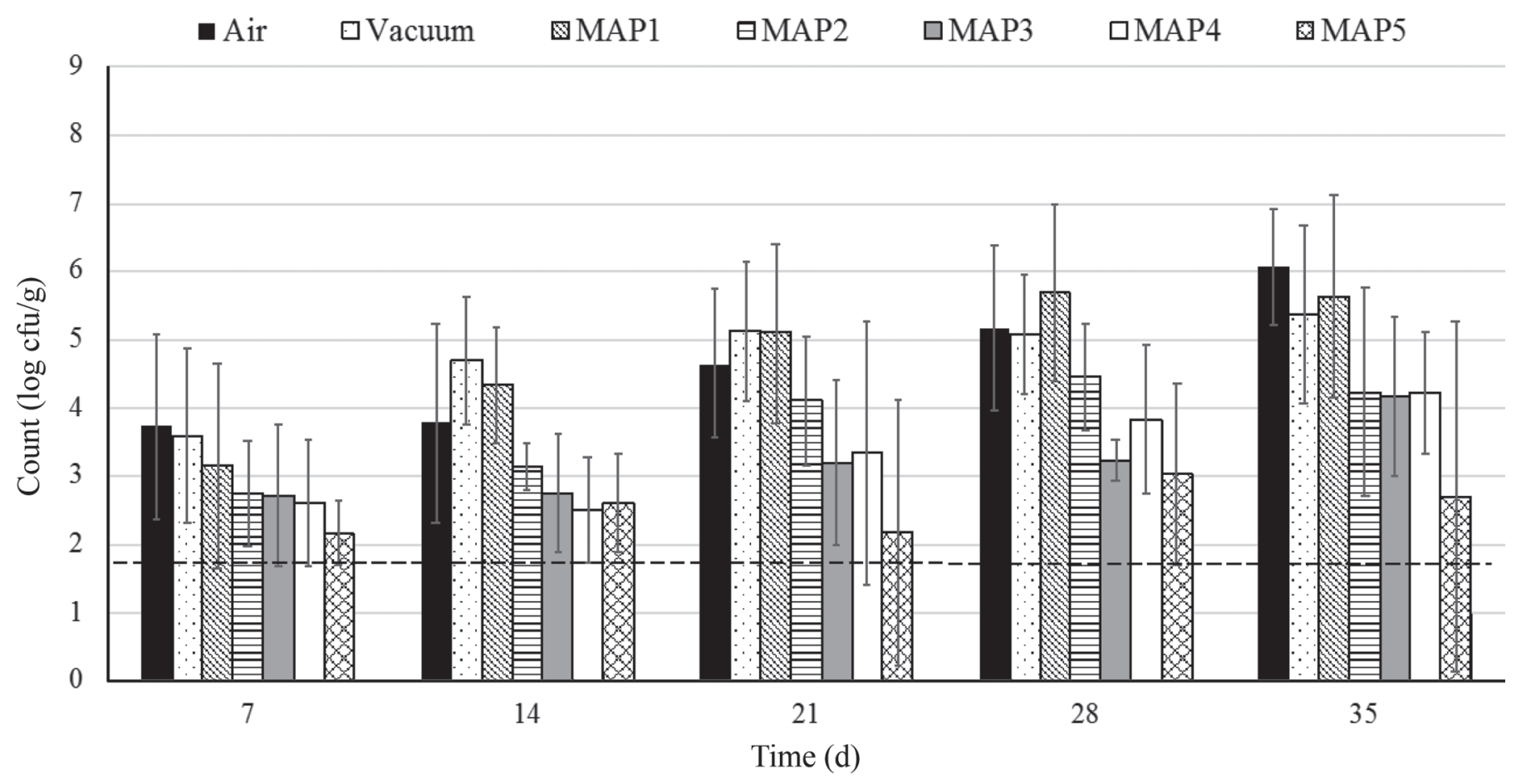

Figure 3. Mean lactic acid bacteria count $( \pm \mathrm{SD})$ in Queso Fresco samples packaged under modified atmospheres during storage at $7^{\circ} \mathrm{C}$ for 35 d. $\mathrm{MAP} 1=100 \% \mathrm{~N}_{2} ; \mathrm{MAP} 2=30 \% \mathrm{CO}_{2}: 70 \% \mathrm{~N}_{2} ; \mathrm{MAP} 3=50 \% \mathrm{CO}_{2}: 50 \% \mathrm{~N}_{2} ; \mathrm{MAP} 4=70 \% \mathrm{CO}_{2}: 30 \% \mathrm{~N}_{2} ; \mathrm{MAP}^{2}=100 \% \mathrm{CO}$. The dashed line indicates initial contamination level at d $0\left(1.59 \pm 1.51 \log _{10} \mathrm{cfu} / \mathrm{g}\right)$.

chrotolerant counts, a treatment effect on yeast and mold counts was observed $(P<0.001)$. Modified atmospheres, as well as packaging under vacuum, inhibited the growth of yeasts and molds on QF to increases of $<1 \log _{10} \mathrm{cfu} / \mathrm{g}$ through $35 \mathrm{~d}$ of storage. In contrast, mean counts in cheeses packaged in air increased $\sim 3$ $\log _{10} \mathrm{cfu} / \mathrm{g}$ at d 7 (Figure 4). Yeast and mold counts in cheeses packaged in air conditions were different than all MAP treatments $(P<0.001)$ through the duration of the study. Differences were also observed between vacuum packaged cheeses when compared with MAP5 $(P=0.005)$. Counts in cheeses stored under $100 \% \mathrm{~N}_{2}$ (MAP1) differed from conditions containing higher $\mathrm{CO}_{2}$ levels, including MAP4 $(P=0.011)$ and MAP5 $(P$ $<0.001)$. The MAP2 QF samples also had higher yeast and mold counts compared with QF packaged under MAP5 conditions $(P=0.033)$ through the duration of the study. The inhibition and reductions in yeast and mold counts in QF packaged under modified atmospheres compared with growth when packaged under air are consistent with previous reports for Mozzarella stored under similar conditions (Alam and Goyal, 2011). The inhibitory effect of $\mathrm{CO}_{2}$ on yeast and mold counts is also in agreement with those reported previously (Alves et al., 1996; Eliot et al., 1998; Dermiki et al., 2008), including reports of reduced counts in vacuum treatments compared with air (Sarais et al., 1996).

\section{Effect of MAP on Listeria monocytogenes Counts}

Listeria monocytogenes contamination can occur at any point or at multiple points in production including milk, curds, and finished cheese. The present study focused on postmanufacture surface contamination of QF. No listeriae were detected in uninoculated samples from each of the 4 batches of cheese. Mean Listeria monocytogenes counts remained near inoculation levels (d $0=4.27 \log _{10} \mathrm{cfu} / \mathrm{g}$ ) for all treatments at $\mathrm{d} 1$ but increased $\sim 2 \log _{10} \mathrm{cfu} / \mathrm{g}$ on cheeses packaged in air $(6.49$ $\left.\log _{10} \mathrm{cfu} / \mathrm{g}\right)$, vacuum $\left(6.29 \log _{10} \mathrm{cfu} / \mathrm{g}\right)$, and MAP1 (6.23 $\log _{10} \mathrm{cfu} / \mathrm{g}$ ) conditions at d 7 (Table 4). In contrast, mean counts in treatments containing $\mathrm{CO}_{2}$ (MAP2-5) increased $\leq 0.4 \log _{10} \mathrm{cfu} / \mathrm{g}$ by d 7 of storage. However, differences in mean counts between treatments at $\mathrm{d} 7$ were not statistically significant due to the variability in counts at this time point resulting from differences in growth of $L$. monocytogenes between replicates. Mean $L$. monocytogenes counts increased $>3 \log _{10} \mathrm{cfu} / \mathrm{g}$ for air, vacuum, and MAP1 treatments at d 14 and remained at $\sim 8 \log _{10} \mathrm{cfu} / \mathrm{g}$ through $35 \mathrm{~d}$. Treatments consisting of $70 \%$ (MAP4) and $100 \% \mathrm{CO}_{2}$ (MAP5) limited increases in mean L. monocytogenes counts to $<1 \log _{10}$ $\mathrm{cfu} / \mathrm{g}$ higher than initial inoculation through $14 \mathrm{~d}$ (5.25 and $4.86 \log _{10} \mathrm{cfu} / \mathrm{g}$, respectively) and $\sim 1.5 \log _{10} \mathrm{cfu} / \mathrm{g}$ through $21 \mathrm{~d}$ (5.8 and $5.6 \log _{10} \mathrm{cfu} / \mathrm{g}$, respectively). 
As shown in Table 4, L. monocytogenes counts were significantly higher than initial inoculation levels (d 0 $=4.27 \log _{10} \mathrm{cfu} / \mathrm{g}$ ) on cheeses stored in air, vacuum, and MAP1 conditions at $\mathrm{d} 7\left(6.49,6.29\right.$, and $6.23 \log _{10}$ $\mathrm{cfu} / \mathrm{g}$, respectively). Counts within each of these treatments did not increase significantly through subsequent time points after d 14. In contrast, L. monocytogenes counts increased to levels significantly higher than inoculation (d 0) on cheeses stored in MAP2 and MAP3 on d $21(P=0.022$ and $P=0.019$, respectively), on d 28 for MAP4 $(P=0.012)$, and on d 35 for cheese stored under MAP5 $(P=0.045)$ conditions (Table 4). Although no statistically significant differences in counts between treatments were observed at d 1 and 7 , between treatment differences in L. monocytogenes counts were observed on d 14, 21, and 28 (Table 4). Counts were similar for all treatments again at d 35 (Table 4). Overall, treatment and time effects as well as the treatment $\times$ time interaction were significant $(P$ $<0.001$ each). Significant treatment $\times$ time interactions were observed between air, vacuum, and MAP1 when each were compared with MAP2, MAP3, MAP4, and MAP5. Treatment and time effects were observed when MAP2 was compared with MAP5 $(P<0.05$ and $P<0.001)$. In terms of listeristatic treatments, mean L. monocytogenes counts increased $>1 \log _{10} \mathrm{cfu} / \mathrm{g}$ by d 7 for air, vacuum, and MAP1 conditions; d 14 for
MAP2 and MAP3; and d 21 for MAP4 and MAP5 conditions. Previous research on surface inoculated cheese has also reported that increasing the $\mathrm{CO}_{2}$ content of MAP conditions (0-20\%) increased the inhibition of $L$. monocytogenes growth on cheese (Whitley et al., 2000). Olarte et al. (2002) investigated the effect of MAP on the growth of L. monocytogenes in fresh goat cheese produced from contaminated milk, which has a similar composition to QF (no starter culture, near-neutral $\mathrm{pH}$, low salt content, and high moisture content), and found that MAP conditions containing $100 \% \mathrm{CO}_{2}$ reduced $L$. monocytogenes growth rates but did not inhibit growth altogether even when stored at refrigeration temperatures (Olarte et al., 2002). Based on the similarities in L. monocytogenes growth in the present study and those of Olarte et al. (2002), it is possible that the MAP conditions used here would be similarly effective against L. monocytogenes present in $\mathrm{QF}$ as the result of contaminated milk or curd. However, additional studies would be needed to test this assumption. Although increasing $\mathrm{CO}_{2}$ content inhibits the outgrowth of spoilage microorganisms, thereby increasing the shelf life of $\mathrm{QF}$, the growth of the facultative anaerobic pathogen L. monocytogenes presents an increasing food safety hazard as shelf life progresses.

In agreement with previous studies (Eliot et al., 1998; Alam and Goyal, 2011), we found that the efficacy of

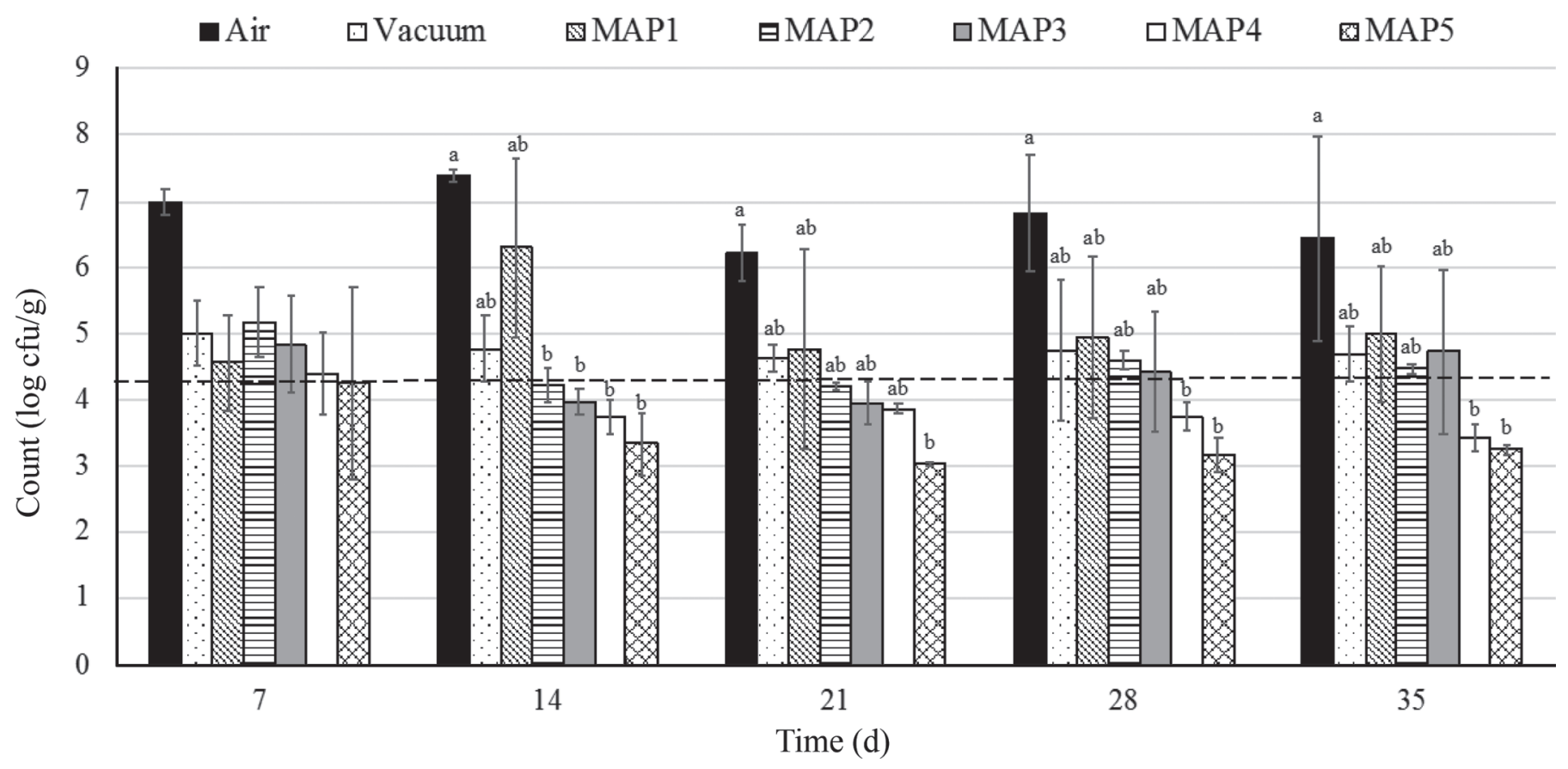

Figure 4. Mean yeast and mold counts $( \pm \mathrm{SD})$ in Queso Fresco samples packaged under modified atmospheres during storage at $7^{\circ} \mathrm{C}$ for 35 d. MAP1 $=100 \% \mathrm{~N}_{2} ; \mathrm{MAP} 2=30 \% \mathrm{CO}_{2}: 70 \% \mathrm{~N}_{2} ; \mathrm{MAP} 3=50 \% \mathrm{CO}_{2}: 50 \% \mathrm{~N}_{2} ; \mathrm{MAP} 4=70 \% \mathrm{CO}_{2}: 30 \% \mathrm{~N}_{2} ; \mathrm{MAP}^{2}=100 \% \mathrm{CO}$. The dashed line indicates initial contamination level at d $0(4.25 \pm 0.53 \log \mathrm{cfu} / \mathrm{g}) .{ }^{\mathrm{a}, \mathrm{b}}$ Values within a time point with different letters differ $(P<0.05)$. 
MAP in controlling spoilage microorganisms increases with increasing $\mathrm{CO}_{2}$ content, whereas conditions consisting of $100 \% \mathrm{~N}_{2}$, vacuum, or air were less effective. The antimicrobial properties of $\mathrm{CO}_{2}$ are thought to be due to several factors including malfunctions in cell membrane, direct physicochemical changes of membrane-located proteins and lipids, inhibition of enzyme systems directly or depression in the rate of enzymatic reactions, inhibition of cell division, and alteration of cell morphology (Khoshgozaran et al., 2012). In addition to the suppression of spoilage microorganisms, Dermiki et al. (2008) concluded that increasing $\mathrm{CO}_{2}$ concentration increased shelf life of whey cheese based on sensory analysis, with $\mathrm{CO}_{2}$ inhibiting lipolysis, proteolysis, and lipid oxidation. Gonzalez-Fandos et al. (2000) also reported increased fat acidity and proteolysis in cheeses packaged under air and vacuum, with the lowest values among $\mathrm{CO}_{2}$-packaged cheeses. Increased fat acidity and proteolysis were attributed to the increases in microbial populations, which were highest in cheeses packaged in air.

With that, MAP is generally effective in prolonging the sensory acceptability of cheeses in terms of taste and odor (Khoshgozaran et al., 2012). Carbon dioxide adsorption may also lead to lower $\mathrm{pH}$ at the surface of products and can potentially alter flavor. For example, Gonzalez-Fandos et al. (2000) reported that $100 \% \mathrm{CO}_{2}$ negatively affected the quality of fresh Cameros cheese and that packaging in $50 \% \mathrm{CO}_{2}: 50 \% \mathrm{~N}_{2}$ and $40 \% \mathrm{CO}_{2}$ : $60 \% \mathrm{~N}_{2}$ were the most effective conditions for extending the shelf life of cheese while maintaining good sensory characteristics (Gonzalez-Fandos et al., 2000). Therefore, in cases where $\mathrm{CO}_{2}$ may negatively increase the acidic taste of products, altering the $\mathrm{CO}_{2}: \mathrm{N}_{2}$ ratio may be needed to balance flavor with microbial control (Scott and Smith, 1971; Kosikowski and Brown, 1973). Although MAP conditions containing $\mathrm{CO}_{2}$ aid in the control of $L$. monocytogenes, the absence of oxygen in MAP conditions may also support the growth of nonproteolytic psychrotolerant strains of Clostridium botulinum (Farber, 1991). Determining the fate of $C$. botulinum in QF stored under different atmospheric conditions was outside the scope of the present study, but previous studies and pathogen modeling suggest that control of nonproteolytic $C$. botulinum growth and toxin production relies on a combination of substrate, redox potential, $\mathrm{pH}$, water activity, as well as headspace composition, temperature, and the presence of preservatives (Farber, 1991; Chen and Hotchkiss, 1993). Although maintaining cold storage temperatures is important for controlling $C$. botulinum growth and toxin production, increasing QF storage temperature would likely result in increased acid development, which would further suppress pathogen growth (Chen and Hotchkiss, 1993) or result in marked spoilage due to growth of contaminants that would deter consumption. It has been suggested that $C$. botulinum incidence in milk is low (Franciosa et al., 1999) and that toxin production in raw and pasteurized milk does not occur because of the product's short, refrigerated shelf life and the inability of this organism to readily compete with the native background flora (Glass et al., 1999). Therefore, additional studies are needed to determine the effect of various MAP conditions on the growth of nonproteolytic C. botulinum in cheeses using different production methods and with varying composition. According to a review by Farber (1991), the presence of starter LAB would enhance the safety of products stored in MAP conditions by keeping background microflora and any pathogenic microorganisms that may be present at very low levels. The manufacture and resulting composition as well as the storage temperatures of the experimental $\mathrm{QF}$ in the present study represent conservatively permissive estimates of commercial practice and excluded the use of starter cultures. Therefore, similar cheeses with higher acidity or produced with starter cultures

Table 4. Listeria monocytogenes counts on Queso Fresco samples packaged under modified atmospheres during storage at $7^{\circ} \mathrm{C}$ for $35 \mathrm{~d}$

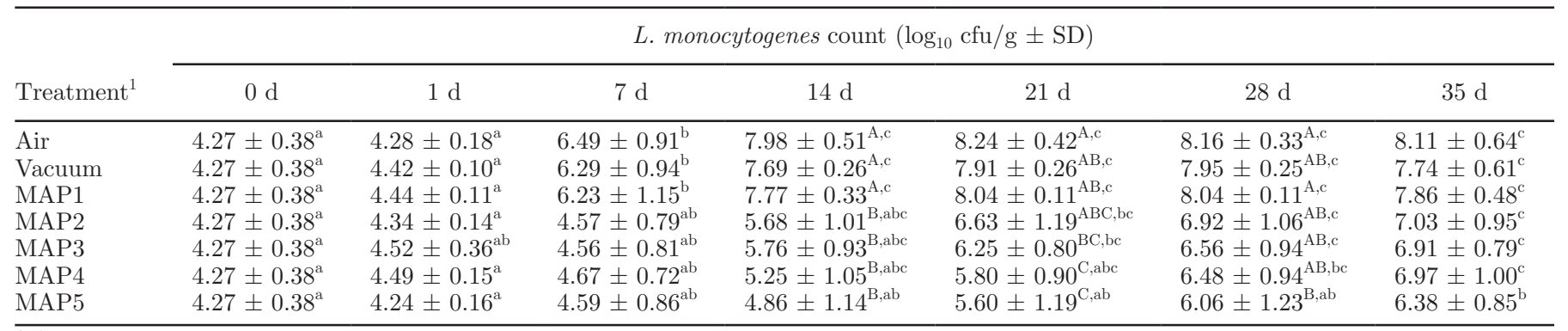

\footnotetext{
${ }^{\mathrm{A}-\mathrm{C}}$ Values within a column with different superscripts differ $(P<0.05)$.

${ }^{\mathrm{a}-\mathrm{C}}$ Values within a row with different superscripts differ $(P<0.05)$.

${ }^{1} \mathrm{MAP} 1=100 \% \mathrm{~N}_{2} ; \mathrm{MAP} 2=30 \% \mathrm{CO}_{2}: 70 \% \mathrm{~N}_{2} ; \mathrm{MAP} 3=50 \% \mathrm{CO}_{2}: 50 \% \mathrm{~N}_{2} ; \mathrm{MAP} 4=70 \% \mathrm{CO}_{2}: 30 \% \mathrm{~N}_{2} ; \mathrm{MAP}^{2}=100 \% \mathrm{CO}_{2}$.
} 
or both would be more likely to suppress growth of unwanted contaminants.

Although the MAP conditions in this study containing $\geq 30 \% \mathrm{CO}_{2}$ (MAP2-5) were effective in limiting $L$. monocytogenes growth, the effects of MAP alone on $L$. monocytogenes growth in other cheeses is underresearched. Combining MAP conditions with other antimicrobial interventions, including antimicrobials and active coatings, may also enhance the antimicrobial activity of MAP against several pathogens (Szabo and Cahill, 1998; Del Nobile et al., 2009; Govaris et al., 2011), warranting further studies.

\section{ACKNOWLEDGMENTS}

This project was supported in part by the National Dairy Council (Rosemont, IL) and the United States Department of Agriculture (USDA) National Institute of Food and Agriculture (NIFA, Washington, DC), Multistate project S1056, accession no. 1003888. Any opinions, findings, conclusions, or recommendations expressed in this manuscript are those of the author(s) and do not necessarily reflect the view of the NIFA, the USDA, or any other sponsors.

\section{REFERENCES}

Alam, T., and G. K. Goyal. 2011. Effect of MAP on microbiological quality of Mozzarella cheese stored in different packages at $7 \pm 1^{\circ} \mathrm{C}$. J. Food Sci. Technol. 48:120-123.

Alves, R. M. V., C. I. G. De Luca Sarantópoulos, A. G. F. Van Dender, and J. De Assis Fonseca Faria. 1996. Stability of sliced Mozzarella cheese in modified-atmosphere packaging. J. Food Prot. 59:838844.

Bermúdez-Aguirre, D., and G. V. Barbosa-Cánovas. 2010. Processing of soft Hispanic cheese ("queso fresco") using thermo-sonicated milk: A study of physicochemical characteristics and storage life. J. Food Sci. 75:S548-S558.

Bishop, J. R., and C. H. White. 1986. Assessment of dairy product quality and potential shelf-life - A review. J. Food Prot. 49:739753.

CDC (Centers for Disease Control and Prevention). 2018. National Outbreak Reporting System (NORS). Foodborne Outbreak Online Database (FOOD Tool). Accessed Jun. 12, 2018. https://wwwn .cdc.gov/norsdashboard/.

Chen, J. H., and J. H. Hotchkiss. 1993. Growth of Listeria monocytogenes and Clostridium sporogenes in cottage cheese in modified atmosphere packaging. J. Dairy Sci. 76:972-977.

Clark, S., H. Warner, and L. Luedecke. 2001. Acceptability of Queso Fresco cheese by traditional and nontraditional consumers. Food Sci. Technol. Int. 7:165-170.

Dansensor. 2017. A guide to MAP gas mixtures. Accessed Nov. 16 2017. https://www.modifiedatmospherepackaging.com/ /media/ Modifiedatmospherepackaging/Brochures/MAP-Poster-Guide $-2014 . \operatorname{ash} x$

Del Nobile, M. A., D. Gammariello, A. Conte, and M. Attanasio. 2009. A combination of chitosan, coating and modified atmosphere packaging for prolonging Fior di latte cheese shelf life. Carbohydr. Polym. 78:151-156.

Dermiki, M., A. Ntzimani, A. Badeka, I. N. Savvaidis, and M. G. Kontominas. 2008. Shelf-life extension and quality attributes of the whey cheese "Myzithra Kalathaki" using modified atmosphere packaging. Lebensm. Wiss. Technol. 41:284-294.

Eliot, S. C., J. C. Vuillemard, and J. P. Emond. 1998. Stability of shredded Mozzarella cheese under modified atmospheres. J. Food Sci. 63:1075-1080.

Ennis, S. R., M. Rios-Vargas, and N. G. Albert. 2011. The Hispanic Population: 2010. 2010 Census Briefs. Report Number: C2010BR-04. Accessed Nov. 14, 2017. https://www.census.gov/ content/dam/Census/library/publications/2011/dec/c2010br-04 .pdf.

Farber, J. M. 1991. Microbiological aspects of modified-atmosphere packaging technology-A review. J. Food Prot. 54:58-70.

Franciosa, G., M. Pourshaban, M. Gianfranceschi, A. Gattuso, L. Fenicia, A. M. Ferrini, V. Mannoni, G. De Luca, and P. Aureli. 1999. Clostridium botulinum spores and toxin in mascarpone cheese and other milk products. J. Food Prot. 62:867-871.

Frank, J. F., and A. E. Yousef. 2004. Tests for Groups of Microorganisms. Pages 227-248 in Standard Methods for the Examination of Dairy Products. 17th ed. H. M. Wehr and J. F. Frank, ed. American Public Health Association, Washington, DC.

Genigeorgis, C., M. Carniciu, D. Dutulescu, and T. B. Farver. 1991a. Growth and survival of Listeria monocytogenes in market cheeses stored at 4 to $30^{\circ} \mathrm{C}$. J. Food Prot. 54:662-668.

Genigeorgis, C., J. H. Toledo, and F. J. Garayzabal. 1991b. Selected microbiological and chemical characteristics of illegally produced and marketed soft Hispanic-style cheeses in California. J. Food Prot. 54:598-601.

Glass, K. A., K. M. Kaufman, A. L. Smith, E. A. Johnson, J. H. Chen, and J. Hotchkiss. 1999. Toxin production by Clostridium botulinum in pasteurized milk treated with carbon dioxide. J. Food Prot. $62: 872-876$

Gonzalez-Fandos, E., S. Sanz, and C. Olarte. 2000. Microbiological, physicochemical and sensory characteristics of Cameros cheese packaged under modified atmospheres. Food Microbiol. 17:407414.

Gould, B. 2017a. Cheese Production: Cheese, Hispanic-Production Accessed Nov. 14, 2017. http://future.aae.wisc.edu/data/annual _values/by_area $/ 3454$ ?tab $=$ production.

Gould, B. 2017b. Per Capita U.S. Cheese Consumption (Annual): Per Capita Hispanic Cheese Consumption. Accessed Nov. 16, 2017. http://future.aae.wisc.edu/data/annual_values/by_area/2196 $?$ tab $=$ sales.

Govaris, A., E. Botsoglou, D. Sergelidis, and P. S. Chatzopoulou., P.S 2011. Antibacterial activity of oregano and thyme essential oils against Listeria monocytogenes and Escherichia coli $\mathrm{O} 157$ : $\mathrm{H} 7$ in feta cheese packaged under modified atmosphere. Lebensm. Wiss. Technol. 44:1240-1244.

Hooi, R., D. M. Barbano, R. L. Bradley, D. Budde, M. Bulthaus, M. Chettiar, J. Lynch, and R. Reddy. 2004. Chemical and physical methods. Pages 363-536 in H. M. Wehr, and J. F. Frank, ed. Standard methods for the examination of dairy products, 17th ed. American Public Health Association, Washington, DC.

Kasrazadeh, M., and C. Genigeorgis. 1994. Potential growth and control of Salmonella in Hispanic type soft cheese. Int. J. Food Microbiol. 22:127-140.

Kasrazadeh, M., and C. Genigeorgis. 1995. Potential growth and control of Escherichia coli O157: H7 in soft hispanic type cheese. Int. J. Food Microbiol. 25:289-300.

Kennedy, J., V. Jackson, I. S. Blair, D. A. Mc, C. Dowell, C. Cowan and D. J. Bolton. 2005. Food safety knowledge of consumers and the microbiological and temperature status of their refrigerators. J. Food Prot. 68:1421-1430.

Khoshgozaran, S., M. H. Azizi, and N. Bagheripoor-Fallah. 2012 Evaluating the effect of modified atmosphere packaging on cheese characteristics: A review. Dairy Sci. Technol. 92:1-24.

Kosikowski, F. V., and D. P. Brown. 1973. Influence of carbon dioxide and nitrogen on microbial populations and shelf life of Cottage cheese and sour cream. J. Dairy Sci. 56:12-18.

Kozak, S. M., Y. Bobak, and D. J. D'Amico. 2018. Efficacy of antimicrobials applied individually and in combination for controlling 
Listeria monocytogenes as surface contaminants on Queso Fresco. J. Food Prot. 81:46-53.

Laird, D. T., S. A. Gambrel-Lenarz, F. M. Scher, T. E. Graham, and R. Reddy. 2004. Microbiological Count Methods. Standard methods for the examination of dairy products. H. M. Wehr, and J. F. Frank, ed. 17th ed. American Public Health Association, Washington, DC.

Mastromatteo, M., A. Conte, M. Faccia, M. A. Del Nobile, and A. V. Zambrini. 2014. Combined effect of active coating and modified atmosphere packaging on prolonging the shelf life of low-moisture Mozzarella cheese. J. Dairy Sci. 97:36-45.

National Advisory Committee on Microbiological Criteria for Foods (NACMCF). 2010. Parameters for determining inoculated pack/ challenge study protocols. J. Food Prot. 73:140-202.

Olarte, C., E. González-Fandos, M. Giménez, S. Sanz, and J. Portu. 2002. The growth of Listeria monocytogenes in fresh goat cheese (Cameros cheese) packaged under modified atmospheres. Food Microbiol. 19:75-82.

Renye, J. A., G. A. Somkuti, B. Vallejo-Cordoba, D. L. Van Hekken, and A. F. Gonzalez-Cordova. 2008. Characterization of the microflora isolated from queso fresco made from raw and pasteurized milk. J. Food Saf. 28:59-75.
Rosenthal, I., B. Rosen, S. Bernstein, and G. Popel. 1991. Preservation of fresh cheeses in a $\mathrm{CO}_{2}$-enriched atmosphere. Milchwissenschaft 46:706-708.

Sarais, I., D. Piussi, V. Aquili, and M. L. Stecchini. 1996. The behavior of yeast populations in Stracchino cheese packaged under various conditions. J. Food Prot. 59:541-544.

Scott, C. R., and H. O. Smith. 1971. Cottage cheese shelf life and special gas atmospheres. J. Food Sci. 36:78-80.

Szabo, E. A., and M. E. Cahill. 1998. The combined affects of modified atmosphere, temperature, nisin and ALTA $^{\mathrm{TM}} 2341$ on the growth of Listeria monocytogenes. Int. J. Food Microbiol. 43:21-31.

Van Hekken, D. L., and N. Y. Farkye. 2003. Hispanic cheeses: The quest for queso. Food Technol. 57:32-38.

Villar, R. G., M. D. Macek, S. Simons, P. S. Hayes, M. J. Goldoft, J. H. Lewis, L. L. Rowan, D. Hursh, M. Patnode, and P. S. Mead. 1999. Investigation of multidrug-resistant Salmonella serotype Typhimurium DT104 infections linked to raw-milk cheese in Washington State. JAMA 281:1811-1816.

Whitley, E., D. Muir, and W. M. Waites. 2000. The growth of Listeria monocytogenes in cheese packed under a modified atmosphere. J. Appl. Microbiol. 88:52-57. 